\title{
Review
}

Naseer Ahmed'

\section{Cardioprotective mechanism of FTY720 in ischemia reperfusion injury}

\author{
${ }^{1}$ The Aga Khan University, Medical College, Karachi, Pakistan, Phone: +92 213486 4465, E-mail: dr.naseerg9@gmail.com
}

\begin{abstract}
:
Cardioprotection is a very challenging area in the field of cardiovascular sciences. Myocardial damage accounts for nearly $50 \%$ of injury due to reperfusion, yet there is no effective strategy to prevent this to reduce the burden of heart failure. During last couple of decades, by combining genetic and bimolecular studies, many new drugs have been developed to treat hypertension, heart failure, and cancer. The use of percutaneous coronary intervention has reduced the mortality and morbidity of acute coronary syndrome dramatically. However, there is no standard therapy available that can mitigate cardiac reperfusion injury, which contributes to up to half of myocardial infarcts. Literature shows that the activation of sphingosine receptors, which are $G$ protein-coupled receptors, induces cardioprotection both in vitro and in vivo. The exact mechanism of this protection is not clear yet. In this review, we discuss the mechanism of ischemia reperfusion injury and the role of the FDA-approved sphingosine 1 phosphate drug fingolimod in cardioprotection.
\end{abstract}

Keywords: cardioprotection, FTY720, ischemia-reperfusion injury

DOI: $10.1515 / \mathrm{jbcpp}-2019-0063$

Received: March 20, 2019; Accepted: July 6, 2019

\section{Introduction}

\section{Cardioprotection}

Cardiovascular diseases are the most common cause of mortality worldwide and an estimated 17.5 million deaths annually, i.e. one-third of global deaths (World Health Organization, 2016). During the last century, major advances had been made in cardiovascular sciences from noninvasive to interventional procedures such as coronary artery bypass graft surgery (CABG) and cardiac transplantation. Despite all the advances, cardiovascular diseases continue to be the most common cause of morbidity and mortality all over the world. This poses a huge financial burden on the health care system. Myocardial reperfusion is the treatment of choice for acute coronary syndrome (ACS), but abrupt restoration of blood supply exacerbates the tissue injury caused by ischemia, a process called ischemia/reperfusion injury (IRI). One of the proposed mechanisms of this phenomenon is reperfusion-induced imbalance between vasodilatory and vasoconstrictive substances [1]. Efforts to find ways to prevent and counter this injury have triggered the exploration of a whole new concept of cardioprotection.

Currently, 'myocardial IRI' is a hot topic of research and discussion to prevent irreversible myocardial damage and protect ventricular dysfunction, which in turn leads to heart failure. Cardioprotection is usually defined as 'all mechanisms and means that contribute to the preservation of the heart by reducing or even preventing myocardial damage' [2]. Unfortunately, the results of most of the animal studies could not be reproduced in human settings probably due to fundamental differences in the associated risk factors and comorbidities [3], [4].

\section{Myocardial protection related to ischemia-reperfusion injury}

In recent decades, numerous studies have shown that the myocardial cells possess several coping mechanisms aiming to limit the damage of ischemia/reperfusion. These processes are not limited to the myocardium but 
are also activated at areas both near and far from the heart, and they impart protection both in the acute phase after ACS and minimize the long-standing effects of myocardial infarction (MI).

The cellular mechanisms underlying certain phenomena of myocardial cell protection from ischemia/reperfusion (such as pre-conditioning and post-conditioning) remain to be clarified, but they are likely to be numerous and may include elements outside the myocardium. Lately, it has been discovered that ischemic pre- and post-conditioning affects not only cardiomyocytes but also the coronary vasculature by increasing the synthesis of nitric oxide (NO) and by other mechanisms [5]. Furthermore, circulating blood cells play a vital role in cardioprotection [6], [7]. Platelets and red cells confer cardioprotection by releasing several vesicles, e.g. exosome and micro vesicles (MVs), into the blood. Their cardioprotective role is proven by the fact that they are increased during ischemia and reperfusion and their administration reduces post-reperfusion myocardial damage and stimulated revascularization [7]. Platelets play a double role in IRI. They produce various cardioprotective agents, e.g. MVs and platelet activating factor; in contrast, cytokines produced by them are detrimental to cardiomyocytes [8]. The use of drugs to mimic the phenomenon of pre- or post-conditioning in vivo and the prevention of cell death by apoptosis with pharmacological knowledge are possibilities requiring well-developed safety assessment.

Myocardial cell damage in ischemia is mediated by the interplay of several mechanisms at the cellular and individual level. Three basic cellular mechanisms are oxidative stress, apoptosis, and inflammation. All three play a role in ischemia and reperfusion. But the major contribution of inflammation comes into play after reperfusion as described in the following sections.

\section{Oxidative stress}

Oxidative stress is more often associated with elevated levels of reactive oxygen species (ROS) or reactive nitrogen species (RNS) in the cellular and subcellular levels [9]. However, ROS/RNS at suboptimal levels can act as signaling molecules in maintaining the cardiovascular function [10]. On the other hand, increased ROS/RNS levels can induce pathology by damaging lipids, proteins, and DNA [11]. These free radicals also attract polymorphs, further aggravating neutrophil-induced damage [12], [13]. Another mechanism of myocardial damage is by apoptosis induction [15]. ROS production in mitochondria on reperfusion may cause MPTP opening that leads to apoptosis as illustrated in Figure 1. Thus, ROS, depending on their concentration, site of production, and the overall redox equilibrium of the cell, will determine their biological action (beneficial or deleterious) in the tissues. Cardiovascular pathology associated with oxidative stress is observed in several cardiac diseases such as IRI [16], [17]. Mitochondrial antioxidants have proven to be protective in animal models [18]. Plateletderived MVs also act by decreasing oxidative stress [7].

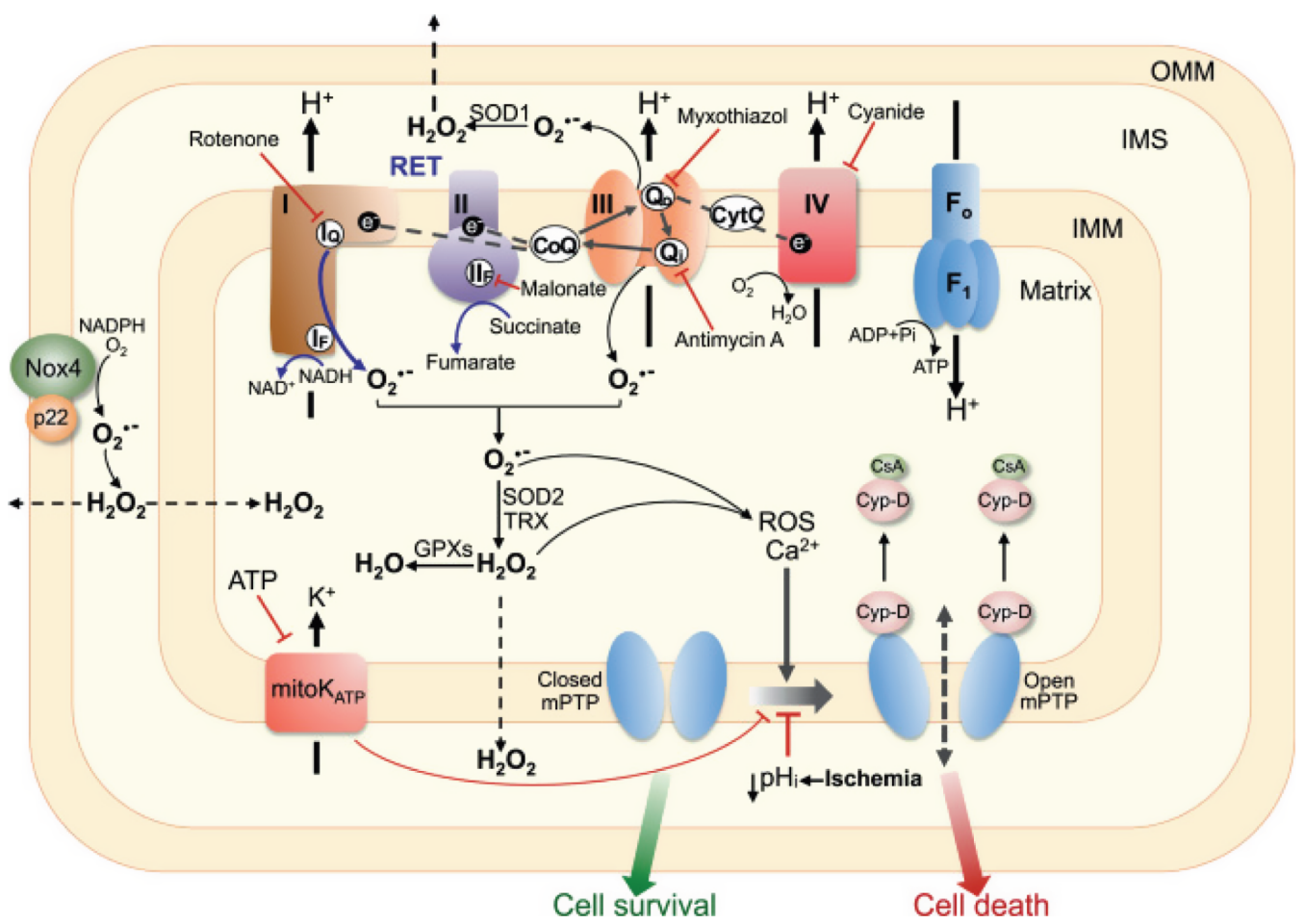


Figure 1: Sources of ROS in mitochondria and mPTP opening upon reperfusion.[19].

Mitochondrial ROS are generated by leakage of electrons from the electron transport chain, causing the incomplete reduction of oxygen to superoxide anion $\left(\mathrm{O}_{2} \bullet^{-}\right)$. In particular, succinate-driven RET leads to mitochondrial matrix superoxide production from complex I early during reperfusion. Mitochondrial $\mathrm{NOX}_{4}$ also contributes to $\mathrm{H}_{2} \mathrm{O}_{2}$ generation. $\mathrm{mPTP}$ formation is inhibited by acidosis and promoted by calcium and ROS [19]. Reprinted from Free Radical Biology and Medicine, Vol. 117, Cadenas S, ROS and redox signaling in myocardial ischemia-reperfusion injury and cardioprotection 76-89, Copyright (2018), with permission from Elsevier.

\section{Apoptosis}

Myocardial ischemia leads to the release of various cytosolic components, which are detected by molecules of the immune system, e.g. toll-like receptors (TLRs) and nod-like receptors (NLRs). These in turn activate a complex inflammatory reaction called 'inflammasome', which results in the activation of the caspase cascade and cytokine release, culminating in cell death [20], [21]. IRI further amplifies these responses by various mechanisms [22], [23], [24], [25]. Inhibition of apoptosis can limit the loss of myocardial cells [26], [27]. Drugs known to have favorable effects in ischemic cardiomyopathy, including angiotensin converting enzyme inhibitors, angiotensin II antagonists, and beta blockers, have shown anti-apoptotic effects in animal models. They do this through the inhibition of the renin-angiotensin system and sympathetic nervous system, which are effectors that, under certain conditions, can trigger apoptosis [28], [29], [30]. Antioxidants can act as antiapoptotic substances because oxidative stress and the generation of ROS may trigger 'intrinsic' apoptosis. In a mouse model of ischemia-reperfusion, in fact, the antioxidant was able to prevent the overexpression of various pro-apoptotic molecules [31]. Potential targets to prevent apoptosis include caspases and endonuclease [32], [33], [34]. Inhibitors of these enzymes were found to be capable of reducing infarct and left ventricular remodeling in experimental models of ischemia-reperfusion damage [31]. One animal study reported that apoptosis was induced only by reperfusion [35].

Insulin-like growth factor is an example of an inhibitor of caspase-3 showing anti-apoptotic effect, which can improve heart function in animal models of cardiomyopathy [36], [37]. However, there are some limitations of the therapeutic strategies aimed at inhibiting apoptosis in clinical practice, especially regarding the carcinogenic potential of such interventions. Furthermore, while in animal models the time and doses of anti-apoptotic drugs are well controlled, there is no well-defined reference to their application in clinical practice.

\section{Inflammation and activation of the complement system}

Restoration of the coronary blood flow triggers an inflammatory response. This inflammatory damage during reperfusion is primarily caused by a massive circulating neutrophil invoked in the reperfused area by the cytokines IL-1ra, IL-6, IL-8, and IL-10, complement activation and adhesive molecules expressed by endothelial and parenchymal cells [19], [38], [39], [40], as well as by the release of cytosolic components from necrotic cells. Complement components play a vital role in IRI by mediating neutrophil adherence to endothelial cells [41], [42], [43] and inducing apoptosis [43]. However, complement activation is also noted in the absence of reperfusion [44], and anti-complement therapies have failed to improve the post-perfusion infarct size [45], [46], making the role of the complement controversial. The recruited neutrophils secrete cytokines and different proteolytic enzymes, leading to lethal tissue damage in the reperfused area [47]; neutrophil accumulation and response is also observed in MI without reperfusion, but this response is accentuated with reperfusion and is reported to be associated with increased size of infarct [13], [48], [49]. The extent of the cellular damage also depends on additional circumstances, including the duration of blood flow interruption particularly in myocardial tissues, the degree of response to the more or less optimal treatment, and the probability of the individual patient survival [50]. Chang et al. studied the role of these and many other clinical factors on post-resuscitation myocardial function [51]. Adrie et al. compared the blood immunochemistry levels in patients who suffered cardiac arrest after resuscitation. Their results showed raised cytokines, cytotoxin, and TNF receptors. IL-6 was 20 times higher in nonsurvivors compared to survivors [52]. Another study reported levels about 50 times exceeding those under physiological values [53]. The increased level of IL-6, TNF- $\alpha$, and endothelin cause vasoconstriction and facilitate neutrophil and platelet adhesion to the endothelium, enhance chemotaxis that leads to systemic abnormalities of vascular function. Some IgM antibodies, for unknown reasons, tend to be deposited in ischemic tissue when blood flow is restored. The complement fractions bind to these antibodies that are activated and induce further cellular damage and increased inflammatory reaction [54]. 


\section{Pharmacological targets for known ischemia-reperfusion injury mechanisms}

The pharmacological cardioprotective strategy to prevent acute global IRI has been tested using different approaches. Over the last few years, multiple pharmacological agents, including volatile anesthetic agents [55], [56], [57], sodium hydrogen exchange inhibitors [58] and statins [59], [60], [61], pharmacological preconditioning [62], [63], anti-oxidants [64], [65], anti-platelets [6], and anti-inflammatory strategies [66], [67], have been explored as potential cardioprotective therapies. However, most preclinical strategies showing cardioprotective effects did not work in clinical settings [68].

\section{Sphingosine-1-phosphate}

Sphingosine-1-phosphate (S1P) present in the plasma is mainly produced by endothelial cells, platelets, erythrocytes [6], and hepatocytes; other sources include platelets, mast cells, endothelial cells, fibroblasts, and the central nervous system [69], [70], [71], [72]. It is a bioactive lysophospholipid (LP) derived from sphingomyelin and ubiquitous in lipid cell membranes [70] having wide function from apoptosis (pro-apoptotic) to protective (anti-apoptotic) as shown in Figure 2. Sphingosine is formed by the enzyme sphingosine kinase. S1P performs its functions by binding to five G-protein receptors (S1P1, S1P2, S1P3, S1P4, and S1P5) [73]. Recently, researchers have discovered that P2Y12 receptor antagonists, a group of antiplatelet drugs, exert their cardioprotective effect by interacting with some factor in platelets to activate sphingosine kinase [6]. This effect is independent of their anti-thrombotic effect.

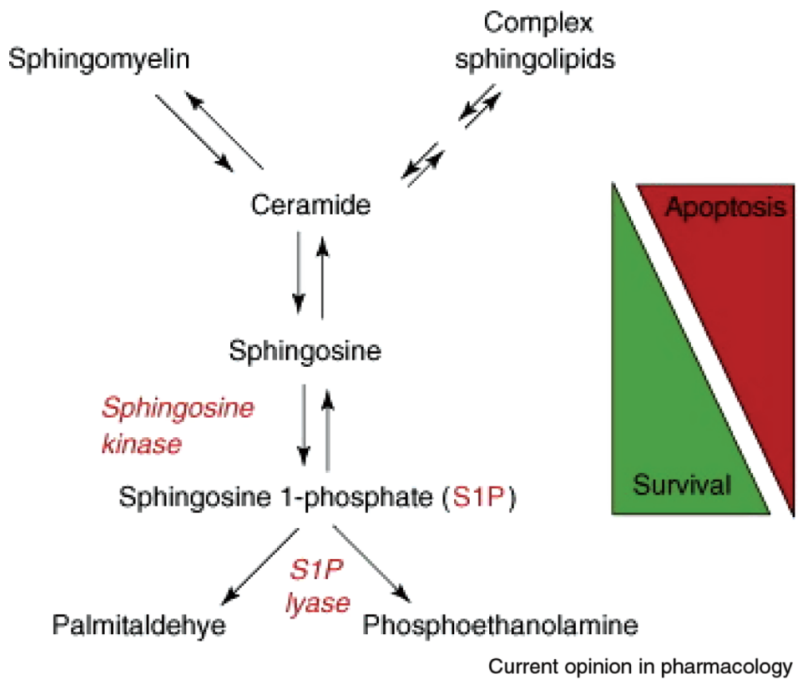

Figure 2: Interconversion of sphingolipids, including the formation of S1P, from sphingosine.

The effects of pro-apoptotic ceramide are countered by S1P, which is generally a survival signal [74]. Reprinted from Current Opinion in Pharmacology, Vol 9, issue 2, Simon Kennedy,Kathleen A Kane,Nigel J Pyne,Susan Pyne , Targeting sphingosine-1-phosphate signalling for cardioprotection, Pages No.194-201, Copyright (2009), with permission from Elsevier.

Among the many effects are cytoprotective antioxidant, immunosuppressive effects [75], and its possible role in reducing ischemia-reperfusion [76]. Recent studies have shown that S1P reduces IRI in the liver [77], kidney [78], and brain [79]. S1P is also able to increase the survival of cardiomyocytes during episodes of hypoxia, whose evidence emerged from in vitro studies [80], [81]. It can also reduce the size of the infarcted area in productions of isolated hearts ex vivo [82], [83].

S1P mediates different physiological functions [84], including cell proliferation, differentiation, and survival, as well as the reorganization of the cytoskeleton, formation of cytoplasmic extensions, cell motility and chemotaxis, intercellular adhesion, and formation of the junctions between cells. It is also involved in maintaining immunity, pulmonary vascular smooth-muscle tone, and endothelial barrier integrity. 


\section{Effects of fingolimod}

Fingolimod has generally been proven to be safe and well tolerated. However, it has presented adverse events of medium to moderate severity, including sinus bradycardia, atrioventricular block, infections, increased liver enzymes, hypertension, and macular edema.

Cardiovascular effects still constitute a major source of concern in the clinical setting, especially after the administration of the first dose of the medicine [85]. These effects have been evaluated through four Phase IV clinical trials: TRANSFORMS, FREEDOMS, FREEDOMS II, and FIRST [86], [87], [88], [89], [90], [91]. These studies have reported that the effect of the drug in reducing heart rate is similar in patients with and without cardiovascular risk factors. Bradycardia induced by the standard FDA-approved dose of $0.5 \mathrm{mg} /$ day was transient, asymptomatic, or caused mild symptoms, but did not require any treatment; it was observed after the first dose but returned to baseline after about a month, despite treatment continuation [92]. Bradycardia and heart block observed at the dosage of $1.25 \mathrm{mg} /$ day required treatment only in two patients [92]; this high dose is not approved by the FDA. Associated symptoms are rare, transient, and usually without clinical consequences. A recent multicenter Phase IV trial (EPOC) confirmed these findings [93].

\section{Cardioprotective mechanism of fingolimod}

Several mechanisms have been claimed to contribute to the cardioprotective effects of fingolimod: by reducing oxidative stress and apoptotic effects, inhibiting inflammatory mediators, and reducing the loss of cardiomyocytes in hypoxic conditions [94], [95], [96]. The new therapeutic perspectives of fingolimod result from increasing knowledge on S1P [70], [97]. S1P on cardiomyocytes binds to the G-protein coupled receptors S1PR1 and S1PR3, leading to the activation of numerous intracellular signal transduction pathways involved in cardioprotective action. S1PR1, in particular, is the main receptor of S1P in cardiomyocytes and typically activates the RISK (reperfusion injury salvage kinase) and SAFE (surviving activating factor enhancement) signal transduction pathways [76], [94], [98]. These pathways mediate the cardioprotective effects of fingolimod. They act through the prevention of apoptosis and oxidative stress actions that contribute to the larger size of the infarct [99], [100], [101]. These pathways are the main molecular cascades that can inhibit mitochondrial transition pore openings [102], [103], [104], [105], and previous in vitro studies claim that S1P can activate these pathways as demosntrated in Figure 3.

In addition to the aforementioned significance of S1P in the activation of the RISK and SAFE pathways, the downstream pathway S1P-R is a potential therapeutic target to prevent peri-infarct. Evidence arising from previous preclinical studies suggests that S1P represents a very promising pharmacological target for mitigating the damage from myocardial ischemia-reperfusion. In ventricular cardiomyocytes of rats [80], [81], S1P increased cardiomyocyte survival during episodes of hypoxia. It is also reported to induce resistance to IRI in rat hearts ex vivo [82], [83]. Another piece of evidence for its cardioprotective effects is the development of greater ischemia-reperfusion myocardial damage in the hearts of mice lacking the enzyme sphingosine kinase, an enzyme necessary for the synthesis of S1P [106], [107]. The role of S1P on the size of the myocardial damage is confirmed, as S1P receptor knockout mice show an area of larger infarct compared to controls [108], [109].

S1P not only reduces myocardial damage but also provides cardioprotection by the metabolism of sphingosine, which also seems to be a key mediator in pre-conditioning and post-conditioning [110]. In fact, both preand post-conditioning can reduce the size of the infarct, which does not take place in hearts lacking sphingosine kinase or S1P receptors [83], [106], [107], [109]. The mitochondrial transition pore opening represents the final step that leads to apoptosis of cardiomyocytes in IRI and is able to trigger oxidative stress that characterizes it. Therefore, preventing the mitochondrial transition pore opening can reduce the infarct size [111], [112].

Previous studies have shown the great benefits of immunosuppression in the prevention of IRI [113]. This function is the basis of fingolimod use for treating multiple sclerosis (MS). It also exerts an immunomodulatory action by sequestering the lymphocytes from peripheral blood and tissues to the lymph nodes and reducing the lymphocyte output from the lymph nodes themselves [70], [114].

Wang et al. observed that in mice with spontaneous coronary artery occlusion, fingolimod reduced the size of the infarcted area (ex vivo) as well as mortality [90]. In addition, it also reduced count of CD4 and CD8 T cells and increased the number of T regulatory cells, suggesting the contribution of immunosuppressive effects of fingolimod to its cardioprotective properties. Together, these findings emphasize that S1P and its synthetic analog fingolimod may have a role in the prevention of IRI. 


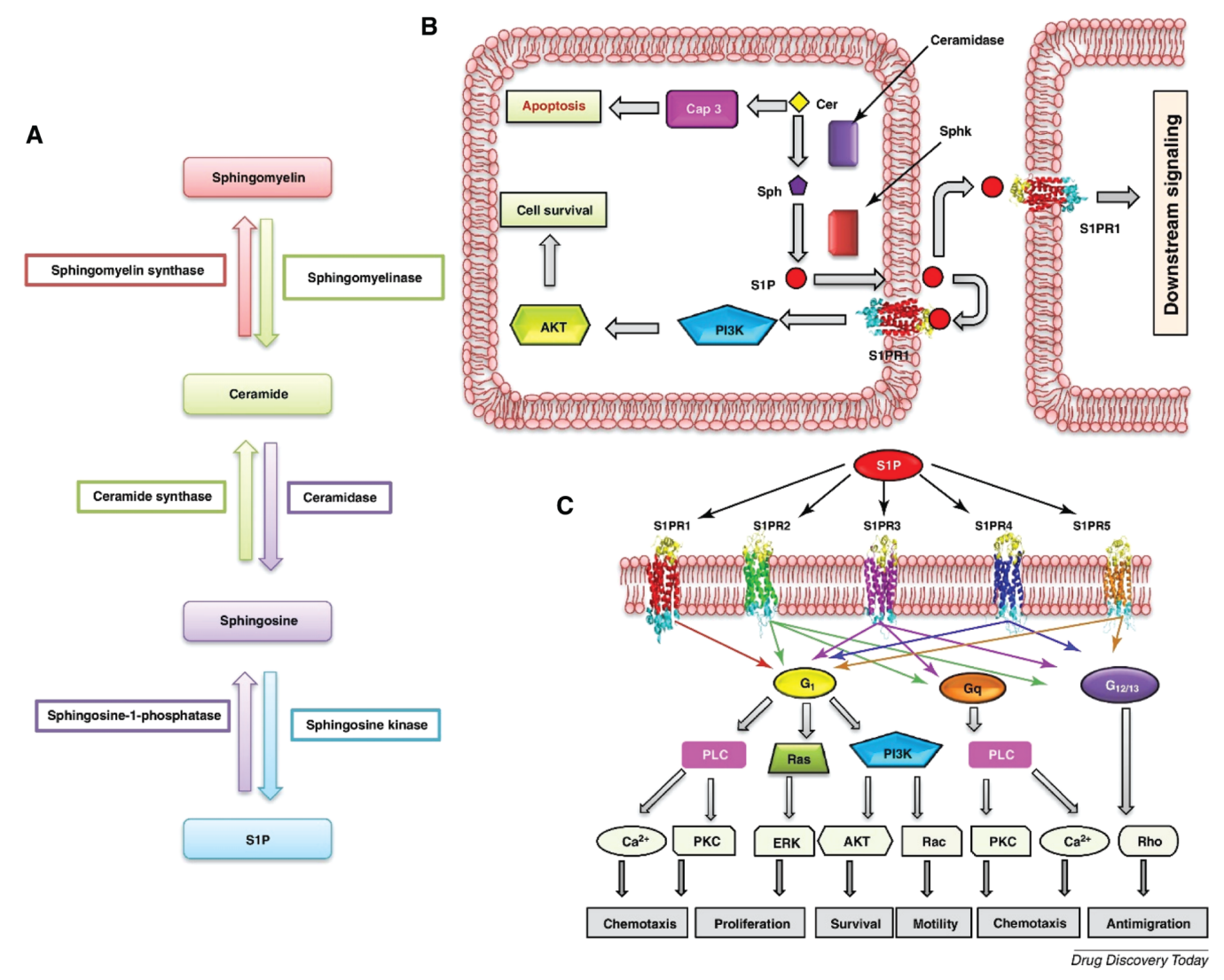

Figure 3: Sphingosine-1-phosphate signaling pathways [115].

(a) The multistep production of sphingosine-1-phosphate (S1P) is governed by several enzymes, including sphingomyelinase, ceramidase and sphingosine kinase (SphK). (b) Ceramidase converts ceramide (Cer) into sphingosine (Sph), which is later phosphorylated by SphK into S1P. Cer leads to the activation of caspase-3 (cap3), resulting in apoptosis, while S1P can also be transported to the extracellular milieu, where it acts in an autocrine or paracrine fashion by binding the S1P receptor (S1PR) and activating phosphoinositide 3-kinase (PI3K) and AKT, leading to cell survival. (c) Binding of S1P to its receptor initiates several downstream signaling pathways via coupling to respective G-proteins. Cartoon diagrams of SIPR1-5 were generated using PyMOL. All protein structures except S1PR1 were modeled using MODELLER 9.13S1PR2, S1PR3, S1PR4 and S1PR5 protein models were generated using the template structure of the S1PR1 (Protein Data Bank id: 3V2W). Transmembrane helices of different receptors are shown in different colors to differentiate them in the membrane. Abbreviations: ERK, extracellular signal-regulated kinase; PKC, protein kinase C; PLC, phospholipase C. [115]. Reprinted from Drug Discovery Today, Vol. 21, Arish M, Husein A, Kashif M, Saleem M, Akhter Y, Rub A, Sphingosine1-phosphate signaling: unraveling its role as a drug target against infectious diseases, page no. 133-42. Copyright (2016), under the terms of Creative Common Attribution License.

Along with its cardioprotective effects, studies on isolated rat hearts have shown that fingolimod also reduces IRI and improves myocardial function [96]. Despite these different confirmations about the various cardioprotective effects, they have not yet been studied in models of large animals and humans.

To further investigate the drug's role in reducing IRI, a study was carried out by Santos-Gallego et al. in a model of myocardial ischemia-reperfusion in pigs, including a short-term protocol (fingolimod administration $15 \mathrm{~min}$ before reperfusion in the study group vs saline in controls) and a long-term protocol (fingolimod $15 \mathrm{~min}$ before reperfusion vs saline in controls; the same treatment repeated once a day for 3 days) [116]. The fingolimod group showed a significant reduction of cardiomyocyte apoptosis [98] in the periphery of ischemic myocardium, resulting in decreased infarct size as compared to controls. It was quantified by terminal deoxynucleotidyl transferase dUTP nick end labeling (TUNEL). The drug also improved the long-term remodeling of heart in addition to these short-term effects. These cardioprotective effects may be attributable to its action as an antioxidant [75], [117], as it decreased the concentration of 8-hydroxydeoxyguanosine, which is a marker of oxidative stress, and increased the levels of the antioxidant superoxide dismutase's enzyme activity [116].

\section{Activation of RISK and SAFE pathways}

Fingolimod reduces cardiomyocyte apoptosis through the activation of the signal transduction pathways RISK [105] and SAFE [118]. Confirming this, the administration of Wortmannin, an inhibitor of the RISK pathway 
(including Akt/ERK/GSK-3 $\beta$ ), or the simultaneous administration of AG490, a SAFE pathway inhibitor (Janus kinase/STAT3), obliterated the drug's anti-apoptotic effect in myocardial tissue [116]. It has been demonstrated that Akt1/2, GSK-3, ERK1/2, and p-STAT-3 were significantly increased in the ischemic myocardial tissue in fingolimod-treated animals, reflecting the cardioprotective effect. Santos-Gallego et al. [116] reported how fingolimod activated Akt1/2, ERK1/2, STAT3- $\beta$, and GSK3 phosphorylation $24 \mathrm{~h}$ after MI [119], [120]. Russo et al. reported that S1P released from platelets plays an important role in protecting the heart by stimulating the ERK, PI3K, and PKC pathways [121].

In addition to promoting the survival pathways Akt1/2 and ERK1/2 [122], fingolimod is also important for the growth of heart cells. Their short-term activation decreases apoptosis, but their continued activation for longer periods causes cardiomyocyte hypertrophy, which is one of the key features of left ventricular remodeling [123], [124], which negatively impacts cardiac health. But, fingolimod reduced the activation of these receptors in the long run, resulting in reduced remodeling [116]. The anti-apoptotic effect of fingolimod is proven in the literature by the decreased activation of the pro-apoptotic markers p53 and caspase-3 [119], [125] and enhanced expression of anti-apoptotic markers including Bcl-2 and kinase C- $\varepsilon$ in fingolimod-treated animals. This anti-apoptotic pathway activation using fingolimod indicates significant reduction in the size of MI area.

\section{Role of fingolimod on ischemic cardiomyopathy}

According to the literature, fingolimod has the potential to reduce the infarcted area, thus leading to the preservation of left ventricular function. This finding has been reported by Santos-Gallego et al., who demonstrated improved ventricular function by cardiac magnetic resonance at early and late phases, where better function (contractility) was preserved in the fingolimod-treated group [116]. Both improved LVEF (left ventricular ejection fraction, and the presence of proper contractile reserve indicated favorable outcomes [126], [127]. Fingolimod also plays important role in post-MI structural remodeling, which is a harbinger of ischemic cardiomyopathy in the long run [116]. Remodeling is characterized by dilation, compensatory hypertrophy, and changes in left ventricular sphericity. Fingolimod attenuated left ventricular tissue remodeling after MI at 1 week in one group and after 1 month in another, which was also confirmed by measuring the ventricular wall thickness by echocardiography [116].

The anti-remodeling effect is also confirmed at the histological level, as demonstrated by reduced collagen deposition in the myocardial interstitium and smaller cardiomyocytes in the fingolimod-treated group [98]. The attenuation of anatomical remodeling is also supported by lower neurohormonal activation, indicated by reduced levels of aldosterone and blood metanephrines. These findings emphasize that the fingolimod group is in harmony with the best anatomical left ventricle level outcomes.

\section{Conclusion}

This review has identified a pharmacological agent that can protect the myocardium from ischemia and reperfusion damage by using fingolimod pre- and post-conditioning. It works by decreasing the oxidative stress, apoptosis, and inhibiting the inflammatory cascades in addition to other signalling pathways in myocardial ischemia reperfusion injury in clinical practice. Translation of studies published on cardioprotective role of fingolimod (FTY720) in experimental models will open new avenues to protect heart during myocardial ischemia and reperfusion.

\section{Acknowledgements}

The author would like to thank Dr. Shahida Perveen for assistance in reviewing this manuscript and the Department of Biological and Biomedical Sciences, Aga Khan University, Karachi, Pakistan, for providing the resources.

Author contributions: Author has accepted the responsibility for the entire content of this submitted manuscript and approved submission.

Research funding: None declared.

Employment or leadership: None declared. 
Honorarium: None declared.

Competing interests: The funding organization(s) played no role in the study design; in the collection, analysis, and interpretation of data; in the writing of the report; or in the decision to submit the report for publication.

Disclosure: This review is part of the author's PhD thesis.

\section{References}

[1] Li ], Zhang $\mathrm{H}$, Zhang C. Role of inflammation in the regulation of coronary blood flow in ischemia and reperfusion: mechanisms and therapeutic implications. J Mol Cell Cardiol 2012;52:865-72.

[2] Kubler W, Haass M. Cardioprotection: definition, classification, and fundamental principles. Heart 1996;75:330-3.

[3] Dirksen MT, Laarman G], Simoons ML, Duncker D]. Reperfusion injury in humans: a review of clinical trials on reperfusion injury inhibitory strategies. Cardiovasc Res 2007;74:343-55.

[4] McCafferty K, Forbes S, Thiemermann C, Yaqoob MM. The challenge of translating ischemic conditioning from animal models to humans: the role of comorbidities. Dis Model Mech 2014;7:1321-33.

[5] Gattullo D, Linden R], Losano G, Pagliaro P, Westerhof N. Ischaemic preconditioning changes the pattern of coronary reactive hyperaemia in the goat: role of adenosine and nitric oxide. Cardiovasc Res 1999;42:57-64.

[6] Russo I, Penna C, Musso T, Popara ], Alloatti G, Cavalot F, et al. Platelets, diabetes and myocardial ischemia/reperfusion injury. Cardiovasc Diabetol 2017;16:71.

[7] Davidson SM, Andreadou I, Barile L, Birnbaum Y, Cabrera-Fuentes HA, Cohen MV, et al. Circulating blood cells and extracellular vesicles in acute cardioprotection. Cardiovasc Res 2019;115:1156-66.

[8] Penna C, Alloatti G, Cappello S, Gattullo D, Berta C, Mognetti B, et al. Platelet-activating factor induces cardioprotection in isolated rat heart akin to ischemic preconditioning: role of phosphoinositide 3-kinase and protein kinase C activation. Am J Physiol Heart Circ Physiol 2005;288: $\mathrm{H} 2512-20$.

[9] Navarro-Yepes ], Burns M, Anandhan A, Khalimonchuk O, del Razo LM, Quintanilla-Vega B, et al. Oxidative stress, redox signaling, and autophagy: cell death versus survival. Antioxid Redox Signal 2014;21:66-85.

[10] Penna C, Mancardi D, Rastaldo R, Pagliaro P. Cardioprotection: a radical view free radicals in pre and postconditioning. Biochim Biophys Acta 2009;1787:781-93.

[11] Wiseman H, Halliwell B. Damage to DNA by reactive oxygen and nitrogen species: role in inflammatory disease and progression to cancer. Biochem ] 1996;313:17-29.

[12] Patel KD, Zimmerman CA, Prescott SM, McEver RP, McIntyre TM. Oxygen radicals induce human endothelial cells to express GMP-140 and bind neutrophils. J Cell Biol 1991;112:749-59.

[13] Montrucchio G, Alloatti G, Mariano F, Comino A, Cacace G, Polloni R, et al. Role of platelet-activating factor in polymorphonuclear neutrophil recruitment in reperfused ischemic rabbit heart. Am ] Pathol 1993;142:471-80.

[14] [14] Zhou T, Prather ER, Garrison DE, Zuo L. Interplay between ROS and Antioxidants during Ischemia-Reperfusion Injuries in Cardiac and Skeletal Muscle. Int] Mol Sci. 2018 January 31;19(2):417.doi:10.3390/ijms19020417.

[15] Rabkin SW, Kong JY. Nitroprusside induces cardiomyocyte death: interaction with hydrogen peroxide. Am ] Physiol Heart Circ Physiol 2000;279: H3089-100.

[16] Roche E, Romero-Alvira D. Role of oxidative stress in gene expression: myocardial and cerebral ischemia, cancer and other diseases. Med Clin (Barc) 1995;104:468-76.

[17] Cuzzocrea S, Riley DP, Caputi AP, Salvemini D. Antioxidant therapy: a new pharmacological approach in shock, inflammation, and ischemia/reperfusion injury. Pharmacol Rev 2001;53:135-59.

[18] Adlam V], Harrison JC, Porteous CM, James AM, Smith RA, Murphy MP, et al. Targeting an antioxidant to mitochondria decreases cardiac ischemia-reperfusion injury. FASEB ] 2005;19:1088-95.

[19] Cadenas S. ROS and redox signaling in myocardial ischemia-reperfusion injury and cardioprotection. Free Radic Biol Med 2018;117:76-89.

[20] Zuurbier C], Abbate A, Cabrera-Fuentes HA, Cohen MV, Collino M, De Kleijn DP, et al. Innate immunity as a target for acute cardioprotection. Cardiovasc Res 2019;115:1131-42.

[21] Mastrocola R, Aragno M, Alloatti G, Collino M, Penna C, Pagliaro P. Metaflammation: tissue-specific alterations of the NLRP3 inflammasome platform in metabolic syndrome. Curr Med Chem 2018;25:1294-310.

[22] Cottlieb RA, Burleson KO, Kloner RA, Babior BM, Engler RL. Reperfusion injury induces apoptosis in rabbit cardiomyocytes. ] Clin Invest 1994;94:1621-8.

[23] Dumont EA, Hofstra L, van Heerde WL, van den Eijnde S, Doevendans PA, DeMuinck E, et al. Cardiomyocyte death induced by myocardial ischemia and reperfusion: measurement with recombinant human annexin-V in a mouse model. Circulation 2000;102:1564-8.

[24] Hofstra L, Liem IH, Dumont EA, Boersma HH, van Heerde WL, Doevendans PA, et al. Visualisation of cell death in vivo in patients with acute myocardial infarction. Lancet 2000;356:209-12.

[25] Fliss H, Gattinger D. Apoptosis in ischemic and reperfused rat myocardium. Circ Res 1996;79:949-56.

[26] Ishikawa S, Noma T, Fu HY, Matsuzaki T, Ishizawa M, Ishikawa K, et al. Apoptosis inhibitor of macrophage depletion decreased M1 macrophage accumulation and the incidence of cardiac rupture after myocardial infarction in mice. PLoS One 2017;12:e0187894.

[27] Okubo S, Tanabe Y, Takeda K, Kitayama M, Kanemitsu S, Kukreja RC, et al. Ischemic preconditioning and morphine attenuate myocardial apoptosis and infarction after ischemia-reperfusion in rabbits: role of delta-opioid receptor. Am ] Physiol Heart Circ Physiol 2004;287:H1786-91. 
[28] Oskarsson H], Coppey L, Weiss RM, Li WG. Antioxidants attenuate myocyte apoptosis in the remote non-infarcted myocardium following large myocardial infarction. Cardiovasc Res 2000;45:679-87.

[29] Wang QD, Pernow ], Sjoquist PO, Ryden L. Pharmacological possibilities for protection against myocardial reperfusion injury. Cardiovasc Res 2002;55:25-37.

[30] Eefting F, Rensing B, Wigman ], Pannekoek W], Liu WM, Cramer M], et al. Role of apoptosis in reperfusion injury. Cardiovasc Res 2004;61:414-26.

[31] Yaoita H, Ogawa K, Maehara K, Maruyama Y. Attenuation of ischemia/reperfusion injury in rats by a caspase inhibitor. Circulation 1998;97:276-81.

[32] Leist M, Jaattela M. Four deaths and a funeral: from caspases to alternative mechanisms. Nat Rev Mol Cell Biol 2001;2:589-98.

[33] Borutaite V, Jekabsone A, Morkuniene R, Brown CC. Inhibition of mitochondrial permeability transition prevents mitochondrial dysfunction, cytochrome c release and apoptosis induced by heart ischemia. J Mol Cell Cardiol 2003;35:357-66.

[34] Ekhterae D, Platoshyn O, Zhang S, Remillard CV, Yuan JX. Apoptosis repressor with caspase domain inhibits cardiomyocyte apoptosis by reducing K+ currents. Am J Physiol Cell Physiol 2003;284:C1405-10.

[35] Zhao ZQ, Nakamura M, Wang NP, Wilcox ]N, Shearer S, Ronson RS, et al. Reperfusion induces myocardial apoptotic cell death. Cardiovasc Res 2000;45:651-60.

[36] Otani H, Yamamura T, Nakao Y, Hattori R, Kawaguchi H, Osako M, et al. Insulin-like growth factor-l improves recovery of cardiac performance during reperfusion in isolated rat heart by a wortmannin-sensitive mechanism. J Cardiovasc Pharmacol 2000;35:275-81.

[37] Li Q, Li B, Wang X, Leri A, Jana KP, Liu Y, et al. Overexpression of insulin-like growth factor-1 in mice protects from myocyte death after infarction, attenuating ventricular dilation, wall stress, and cardiac hypertrophy. J Clin Invest 1997;100:1991-9.

[38] Madathil R], Hira RS, StoeckI M, Sterz F, Elrod JB, Nichol G. Ischemia reperfusion injury as a modifiable therapeutic target for cardioprotection or neuroprotection in patients undergoing cardiopulmonary resuscitation. Resuscitation 2016;105:85-91.

[39] Bottiger BW, Bohrer H, Boker T, Motsch ], Aulmann M, Martin E. Platelet factor 4 release in patients undergoing cardiopulmonary resuscitation-can reperfusion be impaired by platelet activation? Acta Anaesthesiol Scand 1996;40:631-5.

[40] Sawa Y, Ichikawa H, Kagisaki K, Ohata T, Matsuda H. Interleukin-6 derived from hypoxic myocytes promotes neutrophil-mediated reperfusion injury in myocardium. J Thorac Cardiovasc Surg 1998;116:511-7.

[41] Yuan Y, Mier RA, Chilian WM, Zawieja DC, Granger H]. Interaction of neutrophils and endothelium in isolated coronary venules and arterioles. Am J Physiol 1995;268:H490-8.

[42] Riedemann NC, Ward PA. Complement in ischemia reperfusion injury. Am ] Pathol 2003;162:363-7.

[43] Vakeva AP, Agah A, Rollins SA, Matis LA, Li L, Stahl GL. Myocardial infarction and apoptosis after myocardial ischemia and reperfusion: role of the terminal complement components and inhibition by anti-C5 therapy. Circulation 1998;97:2259-67.

[44] Vakeva A, Morgan BP, Tikkanen I, Helin K, Laurila P, Meri S. Time course of complement activation and inhibitor expression after ischemic injury of rat myocardium. Am J Pathol 1994;144:1357-68.

[45] Granger CB, Mahaffey KW, Weaver WD, Theroux P, Hochman JS, Filloon TG, et al. Pexelizumab, an anti-C5 complement antibody, as adjunctive therapy to primary percutaneous coronary intervention in acute myocardial infarction: the COMplement inhibition in Myocardial infarction treated with Angioplasty (COMMA) trial. Circulation 2003;108:1184-90.

[46] Mahaffey KW, Granger CB, Nicolau JC, Ruzyllo W, Weaver WD, Theroux P, et al. Effect of pexelizumab, an anti-C5 complement antibody, as adjunctive therapy to fibrinolysis in acute myocardial infarction: the COMPlement inhibition in myocardial infarction treated with thromboLYtics (COMPLY) trial. Circulation 2003;108:1176-83.

[47] Vinten-Johansen ]. Involvement of neutrophils in the pathogenesis of lethal myocardial reperfusion injury. Cardiovasc Res 2004;61:48197.

[48] Adrie C, Laurent I, Monchi M, Cariou A, Dhainaou JF, Spaulding C. Postresuscitation disease after cardiac arrest: a sepsis-like syndrome? Curr Opin Crit Care 2004;10:208-12.

[49] Niemann JT, Rosborough JP, Youngquist S, Shah AP, Lewis R], Phan QT, et al. Cardiac function and the proinflammatory cytokine response after recovery from cardiac arrest in swine. J Interferon Cytokine Res 2009;29:749-58.

[50] Vaahersalo ], Skrifvars MB, Pulkki K, Stridsberg M, Rosjo H, Hovilehto S, et al. Admission interleukin-6 is associated with post resuscitation organ dysfunction and predicts long-term neurological outcome after out-of-hospital ventricular fibrillation. Resuscitation 2014;85:1573-9.

[51] Chang WT, Ma MH, Chien KL, Huang CH, Tsai MS, Shih FY, et al. Postresuscitation myocardial dysfunction: correlated factors and prognostic implications. Intensive Care Med 2007;33:88-95.

[52] Adrie C, Adib-Conquy M, Laurent I, Monchi M, Vinsonneau C, Fitting C, et al. Successful cardiopulmonary resuscitation after cardiac arrest as a "sepsis-like" syndrome. Circulation 2002;106:562-8.

[53] Vgontzas AN, Bixler EO, Lin HM, Prolo P, Trakada G, Chrousos GP. IL-6 and its circadian secretion in humans. Neuroimmunomodulation 2005;12:131-40

[54] Zhang M, Michael LH, Grosjean SA, Kelly RA, Carroll MC, Entman ML. The role of natural IgM in myocardial ischemia-reperfusion injury. ] Mol Cell Cardiol 2006;41:62-7.

[55] Symons ]A, Myles PS. Myocardial protection with volatile anaesthetic agents during coronary artery bypass surgery: a meta-analysis. Br ] Anaesth 2006;97:127-36.

[56] Yu CH, Beattie WS. The effects of volatile anesthetics on cardiac ischemic complications and mortality in CABC: a meta-analysis. Can ] Anaesth 2006;53:906-18.

[57] Kato R, Foex P. Myocardial protection by anesthetic agents against ischemia-reperfusion injury: an update for anesthesiologists. Can ] Anaesth 2002;49:777-91.

[58] Avkiran M, Marber MS. $\mathrm{Na}(+) / \mathrm{H}(+)$ exchange inhibitors for cardioprotective therapy: progress, problems and prospects. ] Am Coll Cardiol 2002;39:747-53.

[59] Pan W, Pintar T, Anton ], Lee VV, Vaughn WK, Collard CD. Statins are associated with a reduced incidence of perioperative mortality after coronary artery bypass graft surgery. Circulation 2004;110:1145-9. 
[60] Di Napoli P, Antonio Taccardi A, Grilli A, Spina R, Felaco M, Barsotti A, et al. Simvastatin reduces reperfusion injury by modulating nitric oxide synthase expression: an ex vivo study in isolated working rat hearts. Cardiovasc Res 2001;51:283-93.

[61] ]ia L, Wang L, Liu W, Qian C, Jiang X, Zhang Z. Fluvastatin inhibits cardiomyocyte apoptosis after myocardial infarction through Toll pathway. Exp Ther Med 2018;16:1350-4.

[62] Lee HT, LaFaro R], Reed CE. Pretreatment of human myocardium with adenosine during open heart surgery. ] Card Surg 1995;10:665-76.

[63] Belhomme D, Peynet ], Florens E, Tibourtine O, Kitakaze M, Menasche P. Is adenosine preconditioning truly cardioprotective in coronary artery bypass surgery? Ann Thorac Surg 2000;70:590-4.

[64] Brunner F, Maier R, Andrew P, Wolkart G, Zechner R, Mayer B. Attenuation of myocardial ischemia/reperfusion injury in mice with myocyte-specific overexpression of endothelial nitric oxide synthase. Cardiovasc Res 2003;57:55-62.

[65] Yoshida T, Maulik N, Ho YS, Alam ], Das DK. H(mox-1) constitutes an adaptive response to effect antioxidant cardioprotection: a study with transgenic mice heterozygous for targeted disruption of the Heme oxygenase-1 gene. Circulation 2001;103:1695-701.

[66] Chao ], Yin H, Yao YY, Shen B, Smith ]r RS, Chao L. Novel role of kallistatin in protection against myocardial ischemia-reperfusion injury by preventing apoptosis and inflammation. Hum Cene Ther 2006;17:1201-13.

[67] Ma C, Jiang Y, Zhang X, Chen X, Liu Z, Tian X. Isoquercetin ameliorates myocardial infarction through anti-inflammation and antiapoptosis factor and regulating TLR4-NF-kappaB signal pathway. Mol Med Rep 2018;17:6675-80.

[68] Jones SP, Tang X-L, Guo Y, Steenbergen C, Lefer D], Kukreja RC, et al. The NHLBI-sponsored Consortium for preclinicAl assESsment of CARdioprotective therapies (CAESAR): a new paradigm for rigorous, accurate, and reproducible evaluation of putative infarct-sparing interventions in mice, rabbits, and pigs. Circ Res 2015;116:572-86

[69] Schwab SR, Cyster JC. Finding a way out: lymphocyte egress from lymphoid organs. Nat Immunol 2007;8:1295-301.

[70] Spiegel S, Milstien S. Sphingosine-1-phosphate: an enigmatic signalling lipid. Nat Rev Mol Cell Biol 2003;4:397-407.

[71] Fukushima N, Ishii I, Contos ]], Weiner JA, Chun ]. Lysophospholipid receptors. Annu Rev Pharmacol Toxicol 2001;41:507-34.

[72] Cardell SE, Dubin AE, Chun ]. Emerging medicinal roles for lysophospholipid signaling. Trend Mol Med 2006;12:65-75.

[73] Noguchi K, Chun J. Roles for lysophospholipid S1P receptors in multiple sclerosis. Crit Rev Biochem Mol Biol 2011;46:2-10.

[74] Kennedy S, Kane KA, Pyne N], Pyne S. Targeting sphingosine-1-phosphate signalling for cardioprotection. Curr Opin Pharmacol 2009;9:194-201.

[75] Xiang SY, Ouyang K, Yung BS, Miyamoto S, Smrcka AV, Chen ], et al. PLCepsilon, PKD1, and SSH1L transduce RhoA signaling to protect mitochondria from oxidative stress in the heart. Sci Signal 2013;6:ra108.

[76] Karliner JS. Sphingosine kinase and sphingosine 1-phosphate in the heart: a decade of progress. Biochim Biophys Acta 2013;1831:203-12

[77] Man K, Ng KT, Lee TK, Lo CM, Sun CK, Li XL, et al. FTY720 attenuates hepatic ischemia-reperfusion injury in normal and cirrhotic livers. Am J Transplant 2005;5:40-9.

[78] Delbridge MS, Shrestha BM, Raftery AT, El Nahas AM, Haylor ]L. Reduction of ischemia-reperfusion injury in the rat kidney by FTY720, a synthetic derivative of sphingosine. Transplantation 2007;84:187-95.

[79] Wei Y, Yemisci M, Kim HH, Yung LM, Shin HK, Hwang SK, et al. Fingolimod provides long-term protection in rodent models of cerebral ischemia. Ann Neurol 2011;69:119-29.

[80] Karliner ]S, Honbo N, Summers K, Gray MO, Coetzl E]. The lysophospholipids sphingosine-1-phosphate and lysophosphatidic acid enhance survival during hypoxia in neonatal rat cardiac myocytes. J Mol Cell Cardiol 2001;33:1713-7.

[81] Tao R, Zhang ], Vessey DA, Honbo N, Karliner JS. Deletion of the sphingosine kinase-1 gene influences cell fate during hypoxia and glucose deprivation in adult mouse cardiomyocytes. Cardiovasc Res 2007;74:56-63.

[82] ] in ZQ, Zhou HZ, Zhu P, Honbo N, Mochly-Rosen D, Messing RO, et al. Cardioprotection mediated by sphingosine-1-phosphate and ganglioside CM-1 in wild-type and PKC epsilon knockout mouse hearts. Am ] Physiol Heart Circ Physiol 2002;282:H1970-7.

[83] Lecour S, Smith RM, Woodward B, Opie LH, Rochette L, Sack MN. Identification of a novel role for sphingolipid signaling in TNF alpha and ischemic preconditioning mediated cardioprotection. ] Mol Cell Cardiol 2002;34:509-18.

[84] Groves A, Kihara Y, Chun J. Fingolimod: direct CNS effects of sphingosine 1-phosphate (S1P) receptor modulation and implications in multiple sclerosis therapy. ] Neurol Sci 2013;328:9-18.

[85] Aguiar C, Batista S, Pacheco R. Cardiovascular effects of fingolimod: relevance, detection and approach. Rev Port Cardiol 2015;34:279-85.

[86] Cohen JA, Barkhof F, Comi C, Hartung HP, Khatri BO, Montalban X, et al. Oral fingolimod or intramuscular interferon for relapsing multiple sclerosis. N Eng ] Med 2010;362:402-15.

[87] Kappos L, Radue EW, O'Connor P, Polman C, Hohlfeld R, Calabresi P, et al. A placebo-controlled trial of oral fingolimod in relapsing multiple sclerosis. N Eng ] Med 2010;362:387-401.

[88] Calabresi PA, Radue EW, Coodin D, Jeffery D, Rammohan KW, Reder AT, et al. Safety and efficacy of fingolimod in patients with relapsing-remitting multiple sclerosis (FREEDOMS II): a double-blind, randomised, placebo-controlled, phase 3 trial. Lancet Neurol 2014;13:545-56

[89] Cold R, Comi C, Palace ], Siever A, Cottschalk R, Bijarnia M, et al. Assessment of cardiac safety during fingolimod treatment initiation in a real-world relapsing multiple sclerosis population: a phase 3b, open-label study. J Neurol 2014;261:267-76.

[90] Wang C, Kim RY, Imhof I, Honbo N, Luk FS, Li K, et al. The immunosuppressant FTY720 prolongs survival in a mouse model of dietinduced coronary atherosclerosis and myocardial infarction. J Cardiovasc Pharmacol 2014;63:132-43.

[91] Khatri B, Barkhof F, Comi G, Hartung HP, Kappos L, Montalban X, et al. Comparison of fingolimod with interferon beta-1a in relapsingremitting multiple sclerosis: a randomised extension of the TRANSFORMS study. Lancet Neurol 2011;10:520-9.

[92] Singer B, Ross AP, Tobias K. Oral fingolimod for the treatment of patients with relapsing forms of multiple sclerosis. Int ] Clin Pract 2011;65:887-95.

[93] Fox E, Edwards K, Burch C, Wynn DR, LaCanke C, Crayton H, et al. Outcomes of switching directly to oral fingolimod from injectable therapies: results of the randomized, open-label, multicenter, Evaluate Patient OutComes (EPOC) study in relapsing multiple sclerosis. Mult Scler Relat Disord 2014;3:607-19.

[94] Waeber C, Walther T. Sphingosine-1-phosphate as a potential target for the treatment of myocardial infarction. Circ ] 2014;78:795-802. 
[95] Zhang ], Honbo N, Coetzl E], Chatterjee K, Karliner ]S, Cray MO. Signals from type 1 sphingosine 1-phosphate receptors enhance adult mouse cardiac myocyte survival during hypoxia. Am J Physiol Heart Circ Physiol 2007;293:H3150-8.

[96] Hofmann U, Burkard N, Vogt C, Thoma A, Frantz S, Ertl C, et al. Protective effects of sphingosine-1-phosphate receptor agonist treatment after myocardial ischaemia-reperfusion. Cardiovasc Res 2009;83:285-93.

[97] Ahmed N, Linardi D, Decimo I, Mehboob R, Cebrie MA, Innamorati G, et al. Characterization and expression of sphingosine 1-phosphate receptors in human and rat heart. Front Pharmacol 2017;8:312.

[98] Ahmed N, Linardi D, Muhammad N, Chiamulera C, Fumagalli G, Biagio LS, et al. Sphingosine 1-phosphate receptor modulator fingolimod (FTY720) attenuates myocardial fibrosis in post-heterotopic heart transplantation. Fron Pharmacol 2017;8:645.

[99] Hausenloy D], Tsang A, Yellon DM. The reperfusion injury salvage kinase pathway: a common target for both ischemic preconditioning and postconditioning. Trends Cardiovasc Med 2005;15:69-75.

[100] Hausenloy D], Tsang A, Mocanu MM, Yellon DM. Ischemic preconditioning protects by activating prosurvival kinases at reperfusion. Am J Physiol Heart Circ Physiol 2005;288:H971-6.

[101] Rossello X, Yellon DM. The RISK pathway and beyond. Basic Res Cardiol 2018;113:2.

[102] Heusch G. Cardioprotection: chances and challenges of its translation to the clinic. Lancet 2013;381:166-75.

[103] Heusch G, Musiolik ], Gedik N, Skyschally A. Mitochondrial STAT3 activation and cardioprotection by ischemic postconditioning in pigs with regional myocardial ischemia/reperfusion. Circ Res 2011;109:1302-8.

[104] Heusch G. Molecular basis of cardioprotection: signal transduction in ischemic pre-, post-, and remote conditioning. Circ Res 2015;116:674-99.

[105] Davidson SM, Hausenloy D, Duchen MR, Yellon DM. Signalling via the reperfusion injury signalling kinase (RISK) pathway links closure of the mitochondrial permeability transition pore to cardioprotection. Int ] Biochem Cell Biol 2006;38:414-9.

[106] Jin ZQ, Zhang ], Huang Y, Hoover HE, Vessey DA, Karliner ]S. A sphingosine kinase 1 mutation sensitizes the myocardium to ischemia/reperfusion injury. Cardiovasc Res 2007;76:41-50.

[107] Comez L, Paillard M, Price M, Chen Q, Teixeira G, Spiegel S, et al. A novel role for mitochondrial sphingosine-1-phosphate produced by sphingosine kinase-2 in PTP-mediated cell survival during cardioprotection. Basic Res Cardiol 2011;106:1341-53.

[108] Means CK, Xiao CY, Li Z, Zhang T, Omens ]H, Ishii I, et al. Sphingosine 1-phosphate S1P2 and S1P3 receptor-mediated Akt activation protects against in vivo myocardial ischemia-reperfusion injury. Am ] Physiol Heart Circ Physiol 2007;292:H2944-51.

[109] Theilmeier G, Schmidt C, Herrmann ], Keul P, Schafers M, Herrgott I, et al. High-density lipoproteins and their constituent, sphingosine1-phosphate, directly protect the heart against ischemia/reperfusion injury in vivo via the $\mathrm{S}_{1} \mathrm{P} 3$ lysophospholipid receptor. Circulation 2006;114:1403-9.

[110] Yellon DM, Hausenloy D]. Myocardial reperfusion injury. N Eng ] Med 2007;357:1121-35.

[111] Piot C, Croisille P, Staat P, Thibault H, Rioufol G, Mewton N, et al. Effect of cyclosporine on reperfusion injury in acute myocardial infarction. N Eng ] Med 2008;359:473-81.

[112] Skyschally A, Schulz R, Heusch G. Cyclosporine A at reperfusion reduces infarct size in pigs. Cardiovasc Drugs Ther 2010;24:85-7.

[113] Yang Z, Day Y], Toufektsian MC, Xu Y, Ramos SI, Marshall MA, et al. Myocardial infarct-sparing effect of adenosine A2A receptor activation is due to its action on CD4+ T lymphocytes. Circulation 2006;114:2056-64.

[114] Brinkmann V, Billich A, Baumruker T, Heining P, Schmouder R, Francis G, et al. Fingolimod (FTY720): discovery and development of an oral drug to treat multiple sclerosis. Nat Rev Drug Discov 2010;9:883-97.

[115] Arish M, Husein A, Kashif M, Saleem M, Akhter Y, Rub A. Sphingosine-1-phosphate signaling: unraveling its role as a drug target against infectious diseases. Drug Discov Today 2016;21:133-42.

[116] Santos-Gallego CC, Vahl TP, Coliasch G, Picatoste B, Arias T, Ishikawa K, et al. Sphingosine-1-phosphate receptor agonist fingolimod increases myocardial salvage and decreases adverse postinfarction left ventricular remodeling in a porcine model of ischemia/reperfusion. Circulation 2016;133:954-66.

[117] Duan Q, Wang X, Wang Z, Lu T, Han Y, He S. Role of mitochondria in neuron apoptosis during ischemia-reperfusion injury. ] Huazhong Univ Sci Technol Med Sci 2004;24:441-4.

[118] Lecour S. Activation of the protective Survivor Activating Factor Enhancement (SAFE) pathway against reperfusion injury: does it go beyond the RISK pathway?] Mol Cell Cardiol 2009;47:32-40.

[119] Wang M, Lu L, Liu Y, Gu G, Tao R]. FTY720 attenuates hypoxia-reoxygenation-induced apoptosis in cardiomyocytes. Exp Mol Pathol 2014;97:218-24.

[120] Shiojima I, Walsh K. Regulation of cardiac growth and coronary angiogenesis by the Akt/PKB signaling pathway. Cenes Dev 2006;20:3347-65.

[121] Russo I, Femminò S, Barale C, Tullio F, Geuna S, Cavalot F, et al. Cardioprotective properties of human platelets are lost in uncontrolled diabetes mellitus: a study in isolated rat hearts. Front Physiol 2018;9:875.

[122] Clerk A, Cole SM, Cullingford TE, Harrison JG, Jormakka M, Valks DM. Regulation of cardiac myocyte cell death. Pharmacol Ther 2003;97:223-61.

[123] van Berlo JH, Maillet M, Molkentin JD. Signaling effectors underlying pathologic growth and remodeling of the heart. ] Clin Invest 2013;123:37-45

[124] Haq S, Choukroun G, Lim H, Tymitz KM, del Monte F, Gwathmey ], et al. Differential activation of signal transduction pathways in human hearts with hypertrophy versus advanced heart failure. Circulation 2001;103:670-7.

[125] Bopassa JC, Ferrera R, Gateau-Roesch O, Couture-Lepetit E, Ovize M. PI 3-kinase regulates the mitochondrial transition pore in controlled reperfusion and postconditioning. Cardiovasc Res 2006;69:178-85.

[126] Kelle S, Roes SD, Klein C, Kokocinski T, de Roos A, Fleck E, et al. Prognostic value of myocardial infarct size and contractile reserve using magnetic resonance imaging. ] Am Coll Cardiol 2009;54:1770-7.

[127] Williams M], Odabashian ], Lauer MS, Thomas ]D, Marwick TH. Prognostic value of dobutamine echocardiography in patients with left ventricular dysfunction. J Am Coll Cardiol 1996;27:132-9. 